Visual performance of the toad (bufo bufo) at low light levels : Retinal ganglion cell responses and prey-catching accuracy

\author{
Aho, A.-C.
}

Springer

1993

Journal of Comparative Physiology A. 1993. 172: 671-682

http://hdl.handle.net/1975/954

http://dx.doi.org/10.1007/BF00195393

Downloaded from Helda, University of Helsinki institutional repository.

This is an electronic reprint of the original article.

This reprint may differ from the original in pagination and typographic detail.

Please cite the original version. 


\title{
Visual performance of the toad (Bufo bufo) at low light levels: retinal ganglion cell responses and prey-catching accuracy
}

\author{
A.-C. Aho ${ }^{1}$, K. Donner ${ }^{1}$, S. Helenius ${ }^{1}$, L. Olesen Larsen ${ }^{2}$, T. Reuter ${ }^{1}$ \\ ${ }^{1}$ Department of Zoology, University of Helsinki, SF-00100 Helsinki, Finland \\ ${ }^{2}$ Laboratory for Comparative Physiology, August Krogh Institute, University of Copenhagen, Denmark \\ Accepted: 25 February, 1993
}

\begin{abstract}
The accuracy of toad snapping towards moving worm dummies under various levels of dim illumination (from absolute threshold to "moonlight") was videorecorded and related to spike responses of retinal ganglion cells exposed to equivalent stimuli. Some toads (at ca. $16{ }^{\circ} \mathrm{C}$ ) successfully snapped at dummies that produced only one photoisomerization per 50 rods per second in the retina, in good agreement with thresholds of sensitive retinal ganglion cells. One factor underlying such high sensitivity is extensive temporal summation by the ganglion cells. This, however, is inevitably accompanied by very long response latencies (around $3 \mathrm{~s}$ near threshold), whereby the information reaching the brain shows the dummy in a position where it was several seconds earlier. Indeed, as the light was dimmed, snaps were displaced successively further to the rear of the dummy, finally missing it. The results in weak but clearly supra-threshold illumination indicate that snaps were aimed at the advancing head as seen by the brain, but landed further backwards in proportion to the retinal latency. Near absolute threshold, however, accuracy was "too good", suggesting that the animal had recourse to a neural representation of the regularly moving dummies to correct for the slowness of vision.
\end{abstract}

Key words: Visual sensitivity - Visual latency - Toad Bufo bufo - Prey-catching

\section{Introduction}

The European common toad (Bufo bufo) manages visually guided prey-catching at light levels so low $(<10 \mu$ lux $)$ that a human observer can see neither the toad nor the woodlice it is feeding on. This observation was first made in nature and later confirmed in laboratory experiments (Larsen and Pedersen 1982). The absolute threshold of the prey-catching behaviour at about $15{ }^{\circ} \mathrm{C}$ corresponds to a retinal illumination producing no more than one or two photoisomerizations per second per 100 rods, which coincides with the response thresholds of the most sensitive retinal ganglion cells (Aho et al. 1988). Since toad ganglion cells under these conditions sum signals from 400-1000 rods over periods of 1.0-2.5 s, threshold responses are typically based on a total of 10-20 photoisomerizations. The relative statistical variation of such small numbers of quanta is large, and the extended temporal summation is a necessary condition for obtaining an image reliable enough to act on from such a sparse photon rain (cf. long exposure times in photography). The price is that vision becomes slow: the first ganglion cell spikes in response to near-threshold intensities appeared some $3 \mathrm{~s}$ after a worm-like stimulus appeared in the receptive field of the cell. How can an animal catch moving prey if the information from the retina reaches the brain with a delay of $3 \mathrm{~s}$ ?

In this work we study the accuracy of snapping towards moving worm-dummies at different low intensities of a blue-green test illumination, from threshold up to "moonlight". The behaviour was video-recorded under additional infrared illumination (essentially invisible to the toad), and the distributions of tongue hit positions in relation to the dummy were analyzed. The results were related to the spike discharges of ganglion cells in the toad eyecup responding to stimuli that imitated the retinal image of the worm-dummy.

We show how a long summation time helps the toad to see in light which is too dim for humans - and how even toad vision finally breaks down when the summation time needed for collecting a (statistically) significant number of photons becomes incompatible with the task of localizing moving prey. A remarkable finding is that, just at the absolute threshold, toads are able to correct the direction of the snap for the slowness of vision. 


\section{Materials and methods}

\section{Animals}

Twelve toads (Bufo bufo L.), selected from an original group of 14 were used in the behavioural experiments: 8 males, 1 female, and 3 juvenile animals that were male-sized but lacked the finger cornification. Their weights were $46 \mathrm{~g}$ (the female) and 16-32 $\mathrm{g}$ (the others) and their lengths from snout to vent were $7.9 \mathrm{~cm}$ (the female) and $5.5-7.1 \mathrm{~cm}$ (the others). The animals were caught in the autumn in southern Finland and kept in hibernating conditions (basins at $4{ }^{\circ} \mathrm{C}$ in near-darkness and without feeding) until late March the following year. They were then transferred to terraria at $15-20^{\circ} \mathrm{C}$ with access to dark shelters. The nights were dark and the daytime illumination was modest, with natural (approximately $14 \mathrm{~h} / 10 \mathrm{~h}$ ) light-dark cycle at the time when the experiments were carried out (from April 9 to May 6).

In the terraria, the toads were fed mealworms ad libitum overnight twice a week. At the time of the experiments, however, they were only given one mealworm immediately after each session. The intervals between sessions varied from one day to one week, so the animals were hungry but not starving.

Woodlouse observations. As we try to relate our laboratory observations to natural prey-catching, we measured the speed of woodlice, Porcellio scaber, moving on a relatively smooth horizontal bark surface $\left(15^{\circ} \mathrm{C}\right.$, high humidity, very weak illumination). The time taken to traverse a distance of $100 \mathrm{~mm}$ was recorded in about 10 runs of each of 10 woodlice (15 mm body length). The mean speed was $10.5 \pm 5.0(\mathrm{SD}) \mathrm{mm} / \mathrm{s}$, the range $3-33 \mathrm{~mm} / \mathrm{s}$.

\section{Snapping experiments}

Snapping apparatus. The snapping chamber was basically as described by Larsen and Pedersen (1982) and Aho et al. (1988). The toad was sitting in a black plastic box with a $80 \mathrm{~mm}$ wide transparent window of antireflex glass in the floor. One $\mathrm{mm}$ beneath the floor, white worm dummies $(3 \times 20 \mathrm{~mm})$ made of plastic tubing attached to a black string were driven by an electric motor at a speed of $13 \mathrm{~mm} / \mathrm{s}$ (the speed of a fairly swift woodlouse, which we thought appropriate when studying the challenges encountered in catching moving prey). The dummies moved over a background of black cardboard and emerged in the window at $7.7 \mathrm{~s}$ intervals; thus only one dummy was visible at a time (see Fig. 1A).

The test light came from a $20 \mathrm{~W}$ halogen lamp with a $525 \mathrm{~nm}$ interference filter, placed $120 \mathrm{~cm}$ above the toad and driven by a stabilized current source. The intensity was reduced as desired by insertion of individually calibrated neutral density filters. This light illuminated the snapping box through an interposed matte plastic diffuser screen. The infrared light for video-recording came from another halogen lamp ( $20 \mathrm{~W}$, maximum emission about $900 \mathrm{~nm}$ ) placed $30 \mathrm{~cm}$ above the toad and provided with a Schott RG edge filter transmitting wavelengths $>850 \mathrm{~nm}$. Great care was taken to eliminate stray light from either of the lamps.

With respect to the video frames recorded under infrared illumination (Fig. 2), it should be noted that the black string to which the dummies are attached, as well as the black floor of the box, reflect much of the infrared, but little of the $525 \mathrm{~nm}$ light (see below). Hence, the dummy/background contrast in the pictures is much weaker than that seen by the toad.

When the toads were sitting in their "start" position (see Fig. 1A), neither of the radiation sources was projected on their retinas. At $850 \mathrm{~nm}$ the quantum sensitivity of toad rods is approximately $10^{-10}$ of their sensitivity to $500 \mathrm{~nm}$ light (extrapolated from data presented by Baylor et al. 1979). Calculations indicate that isomerizations by infrared photons could hardly have influenced the performance of the toads.

The ambient temperature in the experiments was $15-17^{\circ} \mathrm{C}$. The body temperature was checked in separate measurements with a thermocouple attached to the scalp between the eyes. When exposed to both light sources for $5 \mathrm{~min}$ (snapping sessions never lasted longer than $3 \mathrm{~min}$ ) the toads warmed by $1{ }^{\circ} \mathrm{C}$ relative to the set temperature. Deviations due to other causes, e.g. snapping activity, can be neglected (see Putnam and Bennett 1981). Thus the body temperature of the toads in the experiments was not higher than $16-18^{\circ} \mathrm{C}$. The absolute sensitivity of vision is strongly temperaturedependent (Aho et al. 1988, 1993).

Experimental procedure. The experiments were carried out in the daytime. The toads were dark-adapted overnight (at $13-18^{\circ} \mathrm{C}$ ), and just before sessions at the 3 lower light levels, they were further kept in absolute darkness for a minimum of $1 \mathrm{~h}\left(\right.$ at $\left.13-18^{\circ} \mathrm{C}\right)$. They were gently placed in a marked "start" position in front of the transparent window (Fig. 1A). A second experimenter, sitting behind black screens, watched the process on a video monitor.

A toad was removed from the box as soon as it had snapped 4 times, or after a maximum of $3 \mathrm{~min}$. By this we tried to avoid habituation following unsuccessful snapping. Still, it happened fairly often that the toad itself interrupted the session by leaving its position facing the dummies.

Every snap was recorded and investigated. In this study we do not include the rare snaps which did not touch the floor. Neither do we, in our main analysis, include the numerous snaps directed against dummies which were disappearing from the window. About one third of all snaps were such last attempts to catch a disappearing prey.

The video camera was a black-and-white Panasonic WV-BL600 sensitive to wavelengths from 400 to $1000 \mathrm{~nm}$, provided with a zoom

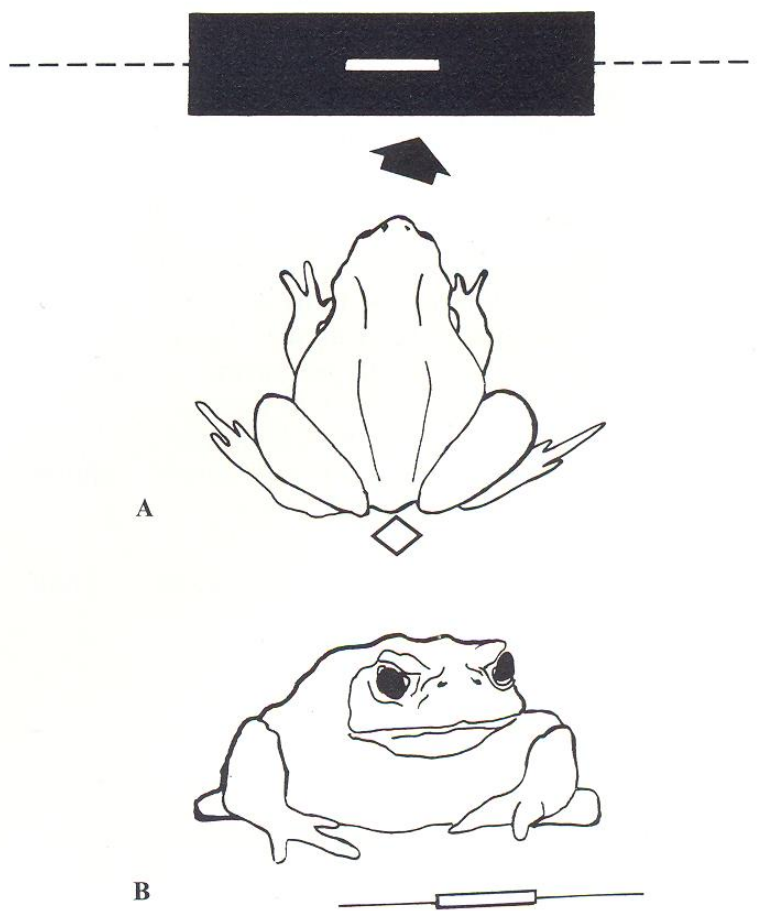

Fig. 1. A The toad in the "start" position facing the window through which a worm-dummy is visible. A mark in the floor (open diamond behind the toad) facilitated reproducible positioning. B Drawing after one of the photographs from which the size of the entrance pupil of the fully dark-adapted toads was determined. Note how the pupil virtually "fills" the eye 
objective M6Z1212. It was connected to a Panasonic NV-J35 video unit and a Panasonic WV5340A monitor. The system recorded 50 frames/s, each covering $4 \mathrm{~ms}$. This sampling rate allowed accurate enough determination of hit position, although it may limit the precision of, e.g., snap duration estimates (according to the criteria of Lescure (1965) who used 1000 images/s, a snap takes only $50 \mathrm{~ms}$ ). Snaps were analyzed from the tapes on a digital video (Blaupunkt RTV-720) and a 14 inch television allowing detailed inspection of all relevant fields.

\section{Ganglion cell recording}

Preparation and recording. The preparation of the eyecup and the methods for extracellular recording of spike responses from single ganglion cells have been described earlier (Copenhagen et al. 1987). The eyes had a caudal-nasal diameter of $6.0-7.0 \mathrm{~mm}$. The fully dark-adapted eyecups were kept at $14.5-16.5^{\circ} \mathrm{C}$ in a semi-enclosed chamber through which moistened oxygen was passed. Our most stable recordings from the same cell lasted for $4 \mathrm{~h}$ and were obtained in eyecups where the vitreous had been drained to a depth of 50-200 $\mu \mathrm{m}$

Thresholds, receptive field sizes and summation times. The protocols for measuring absolute thresholds, receptive field sizes and summation times of retinal ganglion cells closely followed those described by Copenhagen et al. (1987) and Donner (1987). Forty-five s interstimulus intervals were used. Most cells had a very low maintained discharge rate $(<1$ spike or burst per $30 \mathrm{~s})$. The experiments were recorded on tape for detailed analysis of spike patterns and response latencies. Threshold was defined as the stimulus intensity that produced responses on $50 \%$ of the trials.

The summation area (the size of the excitatory receptive field center) was obtained as the ratio of thresholds to small test spots [photoisomerizations within the receptive field] to thresholds to large test fields [photoisomerizations per $\mathrm{mm}^{2}$ retina]. The smal spot must fall wholly within the receptive field center and the large one be larger than the receptive field, but still not so large as to elevate thresholds by activating the inhibitory surround of the receptive field too strongly. The "small" and "large" spots we mainly used subtended $0.1 \mathrm{~mm}$ and 0.5 or $0.8 \mathrm{~mm}$ on the retina, respectively.

The summation time was obtained as the ratio of the threshold to a $1 / 15 \mathrm{~s}$ flash [quanta $/ \mathrm{mm}^{2}$ retina] to the ON-response threshold to a $8 \mathrm{~s}$ square-wave pulse of light [quanta $/ \mathrm{mm}^{2} / \mathrm{s}$ ], delivered with the same test spot.

A single threshold determination based on ca. 20 stimulus presentations has an accuracy better than $\pm 0.1 \log$ units (see Donner 1987). The summation measures determined as differences of log thresholds are thus accurate to within ca. $30 \%$.

To obtain ganglion cell data that would be closely comparable to the behavioural data, we measured absolute thresholds and response patterns of ganglion cells also with a rectangular stimulus equivalent to the retinal image of the prey-dummy in the behavioural experiments (see below). One end of the rectangle was placed over the receptive field center of the cell. For directionally selective ganglion cells (Reuter and Virtanen 1976), the rectangle was oriented as if the worm were entering the receptive field from the optimum direction. It was presented as an ON-step of light, since pilot experiments showed that the "step" threshold intensity was the same as for a rectangle moved across the receptive field at "dummyspeed".

\section{Calibrations}

The red rod mosaic. The rod mosaic in $300.0064 \mathrm{~mm}^{2}$ central samples from 5 retinas carefully mounted in Ringer solution was traced using $\times 1880$ magnification and a drawing tube. The mean density of red rods was $11600 / \mathrm{mm}^{2}$ (range $10900-13000$ ). In addition, there were green rods constituting about $15 \%$ of the total number of rods. Absorption in green rods of the $525 \mathrm{~nm}$ stimulus light is negligible compared with that in red rods (Donner and Reuter 1962; Reuter and Virtanen 1976). The red rod outer segments, also mounted in Ringer solution, were $45.0 \pm 3.0 \mu \mathrm{m}$ long and $7.4+0.8 \mu \mathrm{m}$ in diameter. Thus, the red rod mosaic of Bufo bufo is less dense than that of Bufo marinus $\left(15000 / \mathrm{mm}^{2}\right)$, but instead the outer segments are thicker. Using the above data we have calculated that $34 \%$ of $525 \mathrm{~nm}$ photons incident on the Bufo bufo retina produce isomerizations in red rods, and that one rod outer segment contains about $3.25 \times 10^{9}$ molecules of rhodopsin. (For calculation principles, see Hemilä and Reuter (1981) and Copenhagen et al. (1987).)

Light intensities and isomerization rates. To calculate the retinal isomerization rates produced by the white dummies in the snapping experiments we used, besides the above histological data, the following values and assumptions. The intensity of the unattenuated $525 \mathrm{~nm}$ light incident at the dummy level in the snapping apparatus was $0.03 \mu \mathrm{W} / \mathrm{cm}^{2}$. (Airam UVM-8 radiometer, correction made for light losses at the transparent glass floor of the snapping box.) The matte white plastic tubing of which the dummies were made reflected $71 \%$ of the incident light (LOMO SF-10 spectrophotometer using magnesium oxide as white reference), while the black cardboard under the dummies reflected $7 \%$. We assumed that the dummy behaved as a perfect matte surface. The remarkably large entrance pupil of dark-adapted toads $\left(7.1 \pm 0.3 \mathrm{~mm}^{2}\right)$ was determined by flash photography face-on (see Fig. 1B), and $9 \%$ of the incoming light was estimated to be reflected from the cornea (Aho et al. 1987). No corrections were made for possible light losses in the lens, vitreous and neural retina. Data by Govardovskii and Zueva (1974) and Jagger (1988) indicate that these media are very clear.

We express the intensity of retinal illumination as the number of photoisomerizations produced per rod and second $\left(\mathrm{Rh} * \mathrm{~s}^{-1}\right)$. The unattenuated $525 \mathrm{~nm}$ light reflected from the dummies produced roughly $200 \mathrm{Rh} * \mathrm{~s}^{-1}$ in the toad retina. (To translate this into units of photoisomerizations per rhodopsin molecule and second $\left(\mathrm{R} * \mathrm{~s}^{-1}\right)$ as used by Aho et al. (1988) note that in Bufo bufo $\left.1 \mathrm{Rh} * \mathrm{~s}^{-1}=3.08 \times 10^{-10} \mathrm{R} * \mathrm{~s}^{-1}\right)$.

Size of the retinal image. The distance between the eye and the dummy does not affect the intensity of the retinal image, only its size. Image size was calculated as described in Aho et al. (1987) on the basis of the model eye of du Pont and de Groot (1974), using the viewing distance observed just before snapping (see Results). The image of the dummy would then cover $0.42 \mathrm{~mm} \times 2.8 \mathrm{~mm}=1.18 \mathrm{~mm}^{2}(13700$ rods $)$ on the retina

\section{Results}

\section{Snapping behaviour}

When a toad catches sight of a moving object of a certain size, it approaches and fixates the object. Once the potential prey is within reach of the sticky tongue, the toad may snap, but normally only if the object moves at that moment (Eikmanns 1955; Lescure 1965, 1982; Ewert 1967; Lock and Collett 1979; Larsen 1984, 1992). The snap itself is so fast that a human observer can hardly see it. Although the tongue may be ejected obliquely (at an angle of even $25^{\circ}$ : Schneider 1954), no adjustment of the direction occurs after the snap is initiated. The behaviour can be described as a sequence of 4 phases: orientation, fixation, snapping and gulping. 

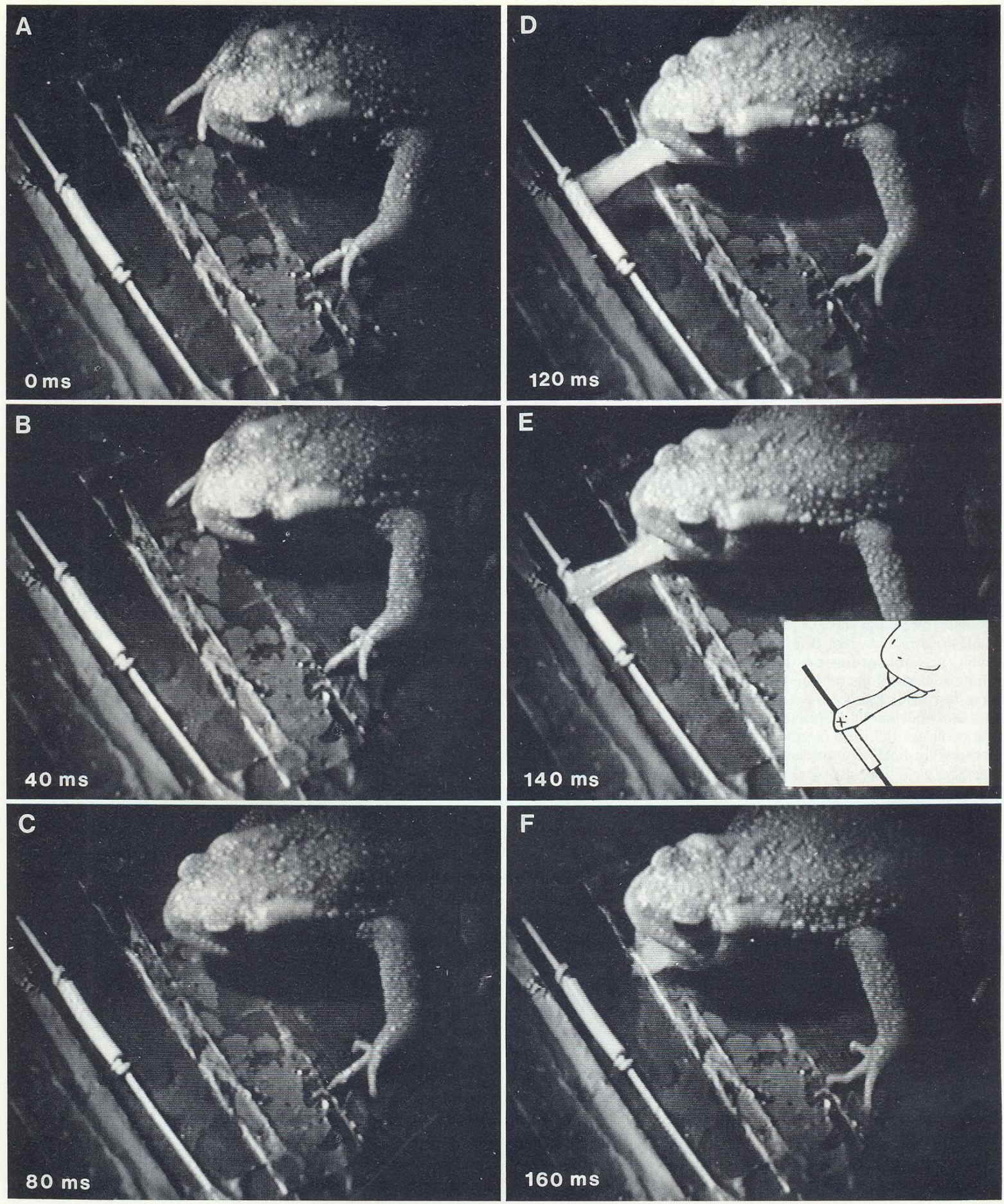

Fig. 2. Video fields of the snapping sequence $(\mathbf{A}-\mathbf{F})$. In $\mathbf{A}$, the snap has not yet started, $\mathbf{B}$ and $\mathbf{C}$ record the forward movement preceding ejection of the tongue $\mathbf{D}$, which has landed in $\mathbf{E}$ and been retracted in $\mathbf{F}$. The relative times are indicated at the lower left-hand

corner of the frames (note that every second field has been omitted between $\mathbf{A}, \mathbf{B}, \mathbf{C}$ and $\mathbf{D})$. Inset in $\mathbf{E}$ shows how the hit position was defined 
Table 1. Summary of snapping session results at 5 light intensities

\begin{tabular}{lllllll}
\hline $\begin{array}{l}\text { Retinal illumination } \\
\text { produced by dummy } \\
\text { projection } \\
\left(\mathrm{Rh} * \mathrm{~s}^{-1}\right)\end{array}$ & $\begin{array}{l}\text { Total time spent } \\
\text { by toad in } \\
\text { apparatus } \\
\text { (min) }\end{array}$ & $\begin{array}{l}\text { Number of } \\
\text { toad snaps }\end{array}$ & $\begin{array}{l}\text { Time per } \\
\text { snap }\end{array}$ & $\begin{array}{l}\text { Range of } \\
\text { snapping } \\
\text { latencies } \\
(\mathrm{s})\end{array}$ & $\begin{array}{l}\text { Distance between } \\
\text { eye and dummy, } \\
\text { mean } \pm \text { s.d. } \\
(\mathrm{mm})\end{array}$ & $\begin{array}{l}\text { Distance along the } \mathrm{x} \text {-axis from } \\
\text { front edge of prey dummy to } \\
\text { median tongue hit point } \\
\text { (mm) }\end{array}$ \\
\hline 200 & 29 & 46 & 38 & $1-93$ & $25 \pm 9.4$ & 4.2 \\
2 & 29 & 46 & 37 & $2-130$ & $29 \pm 9.1$ & 10.8 \\
0.1 & 21 & 21 & 59 & $3-155$ & $27 \pm 10.8$ & 17.5 \\
0.02 & 118 & 16 & 443 & $11-185$ & $29 \pm 7.3$ & 19.2 \\
0.01 & 25 & 0 & - & & - & - \\
\hline
\end{tabular}

The sequence of video frames (technically speaking, fields) in Fig. 2(A-F) presents the fast snapping phase. Frame B $(40 \mathrm{~ms})$ already shows a small forward movement of the nose relative to A, and in E $(140 \mathrm{~ms})$, the tip of the tongue has landed on the transparent floor above the front end of the dummy. From such frames we determined the duration of the snap and the centre of the hit point (frame E, inset). Duration was defined as the interval between the first forward movement of the nose and the hit of the tongue. Eighteen series of frames were analyzed, 4 or 6 from each of the 4 light levels where snapping occurred (see below). The duration of the snap was $137 \pm 25 \mathrm{~ms}$ (range $80-200 \mathrm{~ms}$ ), with no evident dependence on light level. The distance between the dummy and the cornea at the moment when a snap was initiated determined from all snaps was $28 \pm 9 \mathrm{~mm}$ (range 9-51 mm). This distance showed no clear correlation with the size of the toad, nor was any effect of light level observed (Table 1).

\section{Absolute threshold for snapping}

In a previous study devoted to the absolute sensitivity of toad vision (Aho et al. 1988), we observed rare but statistically significant snapping at a light level corresponding to a retinal dummy-image intensity of $0.01 \mathrm{Rh} * \mathrm{~s}^{-1}$. We therefore started the present series of experiments at this intensity, with one session for each of the 12 toads. However, although toads were sitting in the correct position for a total of $25 \mathrm{~min}$, not a single snap towards a dummy was recorded (Table 1). Several of the toads showed restless behaviour and began to look up at the "moon" formed by the illuminated area on the diffuser screen. One snapped upwards. Another one fixated the dummies but did not snap. Thus, none of the present individuals quite attained the highest sensitivity represented in our earlier material. This might be due to small differences in the experimental situation (infrared illumination warming the toad (see Methods) and higher dummy-speed decreasing temporal summation (see Discussion)).

The lowest illumination that yielded a sufficient amount of data for analysis of snapping accuracy was $0.02 \mathrm{Rh} * \mathrm{~s}^{-1}$. During 3 sessions with each toad at this intensity (118 toad-minutes in all), we recorded 16 snaps towards fully visible dummies, and a total of 32 snaps. The proportions of snapping toads in the 3 series of

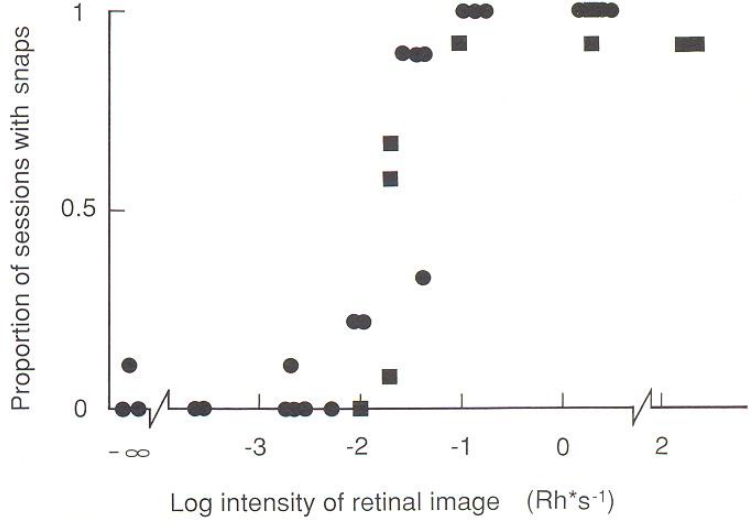

Fig. 3. The proportion of sessions where snaps occurred (ordinate) at different illumination levels. The abscissa gives the intensity of the retinal image of the dummy $\left(\mathrm{Rh} * \mathrm{~s}^{-1}\right)$

sessions were $1 / 12,8 / 12$ and $7 / 12$. At the 3 higher intensities used in the present series of experiments (see below) the proportions of snapping toads approached 12/12.

In Fig. 3 these proportions are plotted against light intensity (squares). The previously published results of Aho et al. (1988) are reproduced for comparison (circles). Except for the failure of snapping at $0.01 \mathrm{Rh} * \mathrm{~s}^{-1}$ in the new material, there is a fair agreement between the two sets of data. If defined as the light intensity where snaps occurred in half of all sessions, the absolute threshold is about $0.02 \mathrm{Rh} * \mathrm{~s}^{-1}$.

\section{Snapping performance at different illumination levels}

Snapping latency. Snapping performance was studied at 4 light levels: $0.02 \mathrm{Rh} * \mathrm{~s}^{-1}$, and at 5,100 and 10000 times higher intensity (Table 1). We analyzed snapping latency, i.e., the time that elapsed from the moment the toad was placed in the apparatus to the first snap, reasoning that it might indicate how readily "prey" is identified at the different illumination levels. In Fig. 4, these latencies are plotted as functions of the intensity of the retinal dummy-image. The filled triangles mark mean latencies from the present material, the open circles mark latencies from single sessions with the 5 most light-sensitive toads from our earlier material.

There is a wide dispersion between sessions (mainly between individuals) at any given intensity, but a clear 


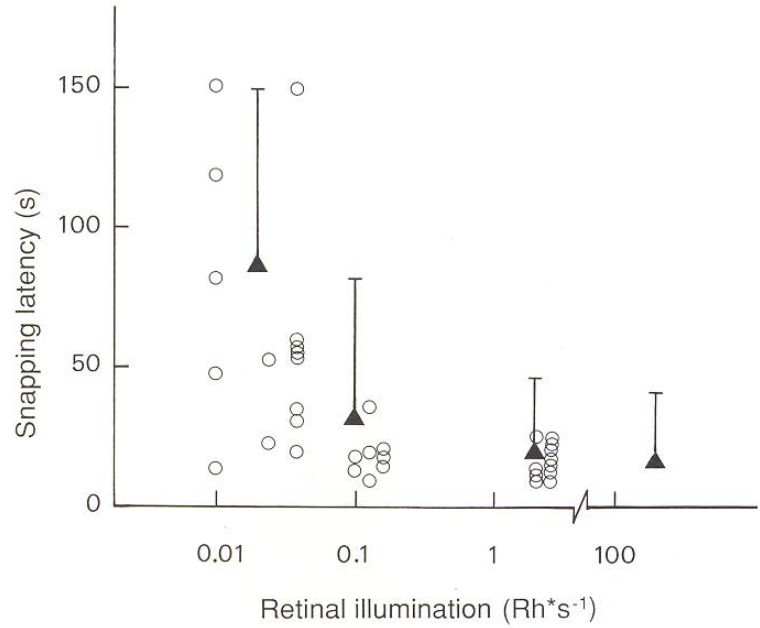

Fig. 4. "Snapping latency", i.e., the time that elapsed from the moment a toad was placed in the apparatus to the first snap. Filled triangles: mean latencies in the present study (error bars give SDs). Open circles: latencies from single sessions from a previous materia (of which absolute sensitivities were analyzed in Aho et al. 1988)

pattern emerges from the mean values. Above $0.1 \mathrm{Rh} * \mathrm{~s}^{-1}$, the mean latency showed little dependence on intensity and was typically between 10 and $25 \mathrm{~s}$. This implies that the toads on average let the first dummy pass but snapped at the second or third. Below $0.1 \mathrm{Rh} * \mathrm{~s}^{-1}$, however, latencies generally grew strongly, so that at $0.02 \mathrm{Rh} * \mathrm{~s}^{-1}$ some 10 dummies were typically allowed to pass before the first snap. This sharp increase is suggestive of mounting difficulties in identifying and/or localizing prey close to the absolute threshold.

Although there were (even at the lowest intensity) some individuals that snapped soon after having been placed in the chamber (Table 1), the minimum latencies convey the same impression. At all higher intensities the most eager toads snapped immediately (within 1-3 s) at the very first dummy that appeared. At the lowest intensity, however, the shortest latency observed was $11 \mathrm{~s}$, implying that no toad ever snapped at the first dummy.

Snapping accuracy. The tongue landing positions in relation to the dummy are plotted in Fig. 5 for all snaps towards fully visible dummies. Each panel corresponds to one light intensity. A regular and interesting trend is apparent. At the highest intensity $\left(200 \mathrm{Rh} * \mathrm{~s}^{-1}\right)$ most hits are well-focussed on the front end of the dummy, at $2 \mathrm{Rh} * \mathrm{~s}^{-1}$ they tend to accumulate just behind the midpoint and are somewhat less well concentrated, and at $0.1 \mathrm{Rh} * \mathrm{~s}^{-1}$ the hits are found in a wide swarm centered on the rear end. At $0.02 \mathrm{Rh} * \mathrm{~s}^{-1}$, finally, a large proportion of the snaps fall behind the dummy. Thus, the snap positions are displaced successively backwards as the light intensity is lowered. The proportion of snaps completely missing the dummy in the longitudinal ( $\mathrm{x}-$ ) direction remains low and fairly constant at the 3 higher intensities $\left(9 \%\right.$ at $200 \mathrm{Rh} * \mathrm{~s}^{-1}$, all in front of the dummy, $7 \%$ and $10 \%$ at, respectively, 2 and $0.1 \mathrm{Rh} * \mathrm{~s}^{-1}$ ) but rises

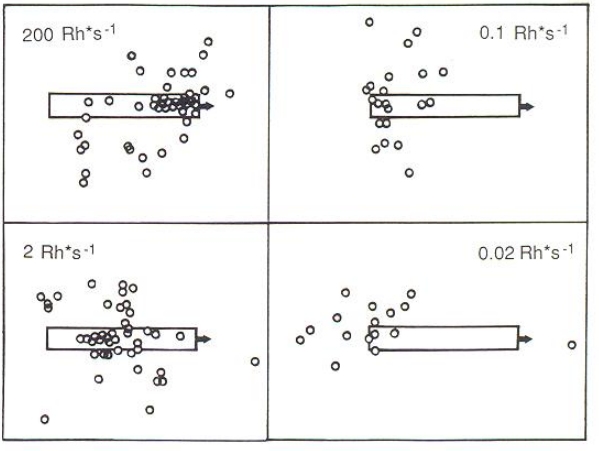

Fig. 5. The tongue hit positions in relation to the dummy at each of the 4 light intensities where snaps were observed. The intensity of the retinal image $\left(\mathrm{Rh} * \mathrm{~s}^{-1}\right)$ is indicated in each panel. The highest intensity $\left(200 \mathrm{Rh} * \mathrm{~s}^{-1}\right)$ corresponds to an illumination that is still somewhat weaker than full moonlight

sharply to $40 \%$ at the lowest intensity (all but one behind the dummy). Within sessions with several snaps, no correction of the snapping direction between the first and the later snaps in the series was observed.

On the other hand, the swarm of snaps remains fairly well-collected even at the lowest intensities. For example, the proportion of misses in the y-direction (perpendicular to the movement) does not grow monotonically. From highest to lowest light intensity, the percentages are $48 \%$, $56 \%, 71 \%$ and $53 \%$. Note that "misses" are here taken as all dots that fall outside the spatial intervals (in the $\mathrm{x}$ or the y-direction) defined by the sides of the rectangle in Fig. 5. This is convenient as a measure of inaccuracy, although in nature many of these "misses" might in fact have caught the prey because of the large size of the sticky tongue.

\section{Ganglion cell responses at absolute threshold}

All visual information reaches the brain through the retinal ganglion cells. We determined absolute (darkadapted) thresholds of 25 ganglion cells to rectangularshaped light stimuli imitating the retinal projection of the dummy, presented as ON-steps (see Methods). Most of the studied cells were of the class 2 type, unresponsive to diffuse light changes, but responding vigorously to dark and bright moving spots or longitudinally moving rectangles (Maturana et al. 1960; Ewert and Hock 1972; Reuter and Virtanen 1976). These cells are likely to provide a crucial part of the information that guides prey-catching, although they cannot be regarded as preyspecific "worm detectors" (Ewert et al. 1978) - probably a toad or frog brain characterizes a stimulus on the basis of the relative activities of all classes of ganglion cells present in a certain retinal region (Maturana et al. 1960; Grüsser and Grüsser-Cornehls 1968; Bäckström et al. 1978).

Table 2 gives some characteristics of the 7 most sensitive of the 25 well-studied dark-adapted ganglion cells. Their absolute response thresholds lie between 0.01 and 
Table 2. Characteristics of the 7 most sensitive ganglion cells out of 25 studied

\begin{tabular}{|c|c|c|c|c|c|c|}
\hline Cell & Cell type & $\begin{array}{l}\text { No. of red rods in } \\
\text { rec. field } \\
\text { R }\end{array}$ & $\begin{array}{l}\text { Summation } \\
\text { time } \\
\mathrm{t}_{\mathrm{i}}(\mathrm{s})\end{array}$ & $\begin{array}{l}\text { Threshold } \\
\text { intensity } \\
\left(\mathrm{Rh} * \mathrm{~s}^{-1}\right)\end{array}$ & $\begin{array}{l}\text { No. of threshold isomerizations } \\
\text { within the receptive field per } \\
\text { summation time } \\
\mathbf{N}\end{array}$ & $\begin{array}{l}\mathrm{SNR}_{\text {in }} \text { at } \\
\text { absolute } \\
\text { threshold }\end{array}$ \\
\hline 1 & on-off & 700 & 2.3 & 0.010 & 15.5 & 2.5 \\
\hline 2 & 2 & 440 & 1.9 & 0.010 & 8.5 & 1.8 \\
\hline 3 & 2 & 700 & 2.6 & 0.013 & 24 & 3.3 \\
\hline 4 & 2 & 1000 & 1.2 & 0.014 & 16.5 & 2.8 \\
\hline 5 & 2 & 880 & 1.3 & 0.016 & 19 & 3.1 \\
\hline 6 & on-off & 1000 & 1.5 & 0.016 & 24 & 3.5 \\
\hline 7 & 2 & 560 & 0.8 & 0.018 & 7.5 & 2.0 \\
\hline Mean & & 750 & 1.65 & 0.014 & 16.4 & 2.7 \\
\hline
\end{tabular}

$\mathrm{SNR}_{\text {in }}=\mathrm{N} / \sqrt{(\mathrm{N}+\mathrm{D})}$ as described in Aho et al. (1987). The number of noise events $\mathrm{D}$ was calculated as $\mathrm{D}=\mathrm{R} \times \mathrm{t}_{\mathrm{i}} \times \mathrm{I}_{\mathrm{D}}$ [rods $\times \mathrm{s} \times$ $\mathrm{Rh} * \mathrm{~s}^{-1}$ ), where $\mathrm{I}_{\mathrm{D}}=0.016 \mathrm{Rh} * \mathrm{~s}^{-1}$ is the rate of spontaneous

isomerization-like events in toad rods at $15^{\circ} \mathrm{C}$ based on Baylor et al. (1980). The cells described as "on-off" responded both to the onset and offset of a small test spot, but were not reliably classified (they were either class 2 or class 3 )

$0.02 \mathrm{Rh} * \mathrm{~s}^{-1}$, i.e., in the threshold range of the snapping behaviour. Eighty \% (20/25) of all the cells studied had thresholds within one log unit of the most sensitive cell. Thus there is a good agreement between the behavioural thresholds and those of sensitive ganglion cells.

\section{Ganglion cell responses at different light levels}

We subsequently recorded discharge patterns in response to the dummy-like stimulus at 4 different light intensities: just above threshold, and at 5, 100 and 10000 times higher intensity (10 responses at each). Observing that in the snapping box $7 \%$ of the $525 \mathrm{~nm}$ illumination was reflected from the black cardboard floor and $71 \%$ from the dummy, we presented these stimuli on full-field background lights such that a 10:1 stimulus/background contrast was always maintained.

Discharge patterns. Representative results from one cell (no. 3 in Table 2) are shown in Fig. 6. As in the snapping experiments, the lowest intensity is $0.02 \mathrm{Rh} * \mathrm{~s}^{-1}$ (panel A). With this dim stimulus, both the latency and spike patterns are seen to vary considerably between responses (apparently due to random fluctuations in the numbers of photons received). The median value is close to $3 \mathrm{~s}$, which is typical of near-threshold responses in sensitive cells at this temperature. (Medians were used rather than means as the latencies in a series of responses to near-threshold stimuli are not normally distributed.) The mean $( \pm \mathrm{SD})$ of the median latencies at $0.02 \mathrm{Rh} * \mathrm{~s}^{-1}$ in 6 cells was $2.9 \pm 1.0 \mathrm{~s}$. (Response latency at the very threshold of sensitive cells is still longer, see Fig. 7). At higher intensities, both latencies and discharge patterns get much shorter and less variable.

The very brief discharges at high intensities (panels $\mathrm{C}$ and especially D) call for a comment. Although the response threshold in a dark-adapted eye is usually the same for a longitudinally moving rectangle and a stationary rectangle delivered as an $\mathrm{ON}$-step, the discharge
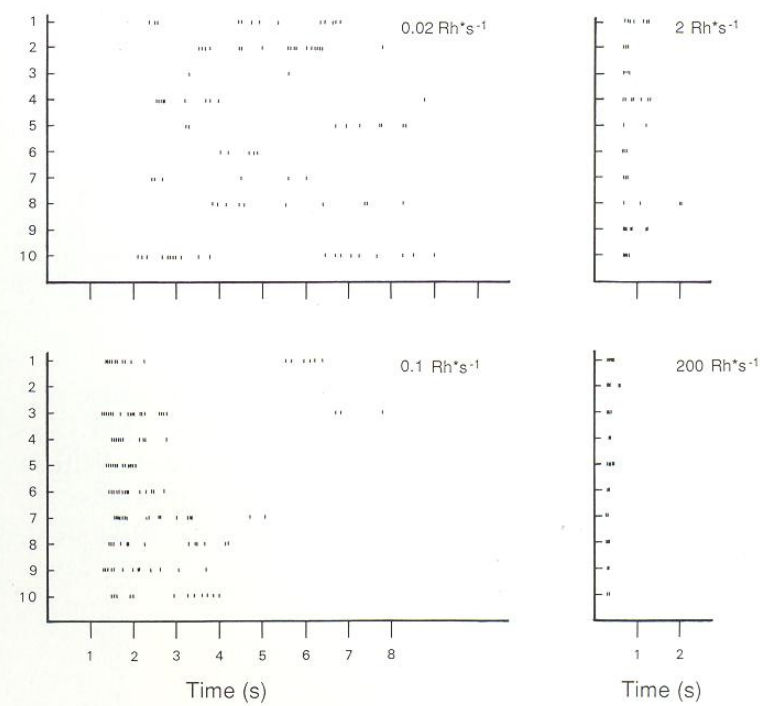

Fig. 6. Spike discharge patterns of one ganglion cell (no. 3 in Table 2) in response to a rectangular dummy-like stimulus presented ten times as an ON-step at each of 4 different intensities. Each dot represents one spike, each row of dots the discharge in response to one presentation of the stimulus. The abscissas give time from stimulus onset (s). The stimulus intensities (indicated in each panel, $\mathrm{Rh} * \mathrm{~s}^{-1}$ ) reproduce the retinal illumination of the dummy image in the behavioural experiments. One discharge at each of the two lowest intensities has been omitted because spontaneous firing during the first second made the response indeterminate. A background light such that stimulus/background contrast was 10:1 was present in all recordings

patterns elicited by the two stimuli are drastically different at higher intensities. The moving stimulus produces much longer discharges, because the onset of the stationary rectangle stimulates the inhibitory surround much more effectively. This inhibitory input curtails the discharges, but will not affect response latencies unless activated so strongly that it arrives at the ganglion cell before the excitatory signal (Donner 1981). As the 


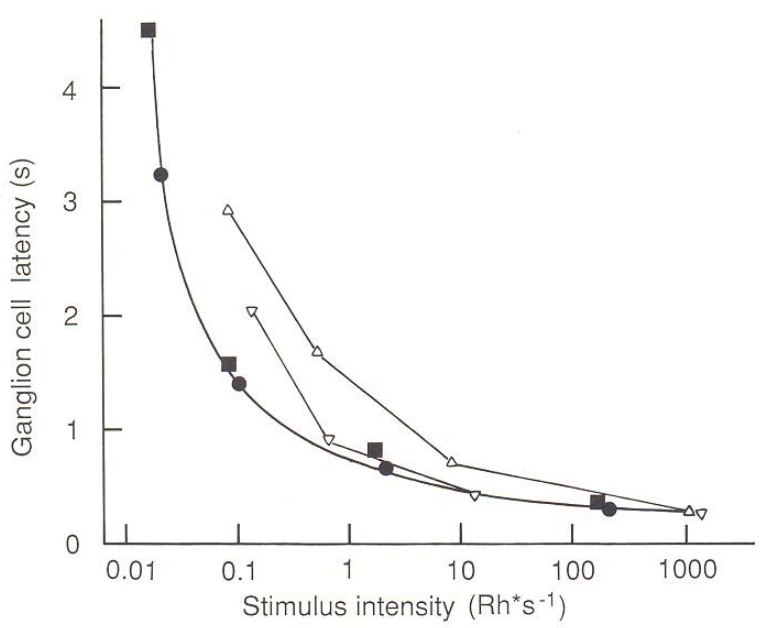

Fig. 7. Ganglion cell response latencies as functions of stimulus intensity $\left(\mathrm{Rh} * \mathrm{~s}^{-1}\right)$. The filled symbols are data from the cell in Fig. 6 (circles from the discharges shown there, squares from another run with the same cell). The smooth full-drawn curve is a theoretical latency function showing times-to-criterion of dark-adapted rod responses (Donner 1989a). The fit was obtained with parameters $n=4$ and $\tau=1.2 \mathrm{~s}$ in the "independent activation model" of Baylor et al. (1974) and rod-to-ganglion-cell transmission delay $0.2 \mathrm{~s}$. This latency fit predicts that the summation time be $2.8 \mathrm{~s}$, close to that observed $(2.6 \mathrm{~s}$, cell no. 3 in Table 2$)$. The curve represents a first-order approximation, neglecting effects of the weak background light. The open triangles (upright and inverted, connected by straight lines) are data from two less sensitive cells

main purpose in these experiments was to measure response latencies with precision, we therefore used ONsteps, which have a well-defined time of onset. With a moving stimulus, there is no independent knowledge on the moment when it effectively enters the receptive field.
Response latencies. That part of visual latency which changes with light intensity appears to originate wholly in the retina (Mansfield and Daugman 1978; Donner 1989a). Thus, response latencies of ganglion cells at the retinal output provide a quantitative measure of how visual information is delayed as the light is dimmed. From recordings such as those in Fig. 6, median response latencies were extracted for each light level and plotted against stimulus intensity. The filled symbols in Fig. 7 show data from the cell in Fig. 6 (circles refer to the responses shown in Fig. 6, squares to another run at $0.1 \mathrm{log}$ unit lower intensities). Also shown (triangles) are latencies from two less sensitive cells. Common to all is a steep shortening of latency as intensity is raised over a narrow range in the threshold region, followed by a slower approach towards a minimum latency of $0.2-0.3 \mathrm{~s}$.

This characteristic intensity-dependence of latencies can be explained from the kinetics of rod photoresponses, if a ganglion cell is assumed always to start firing when the summed rod response has risen to a constant criterion amplitude (Donner 1989a). In Fig. 7, the smooth curve fitted to the filled symbols is a rod time-tocriterion function, with parameters realistic for toad rods at $16{ }^{\circ} \mathrm{C}$ (see figure legend; the position of the curve on the log intensity axis is set by the ganglion cell threshold intensity). The fact that most of the ganglion cell latency originates in phototransduction in the rod outer segment establishes a necessary connection between a long summation time and an even longer response latency to step stimuli (see Discussion).

\section{Snapping displacement and the slowness of vision}

As a consequence of the ganglion cell response latency, the brain receives information on the position of a

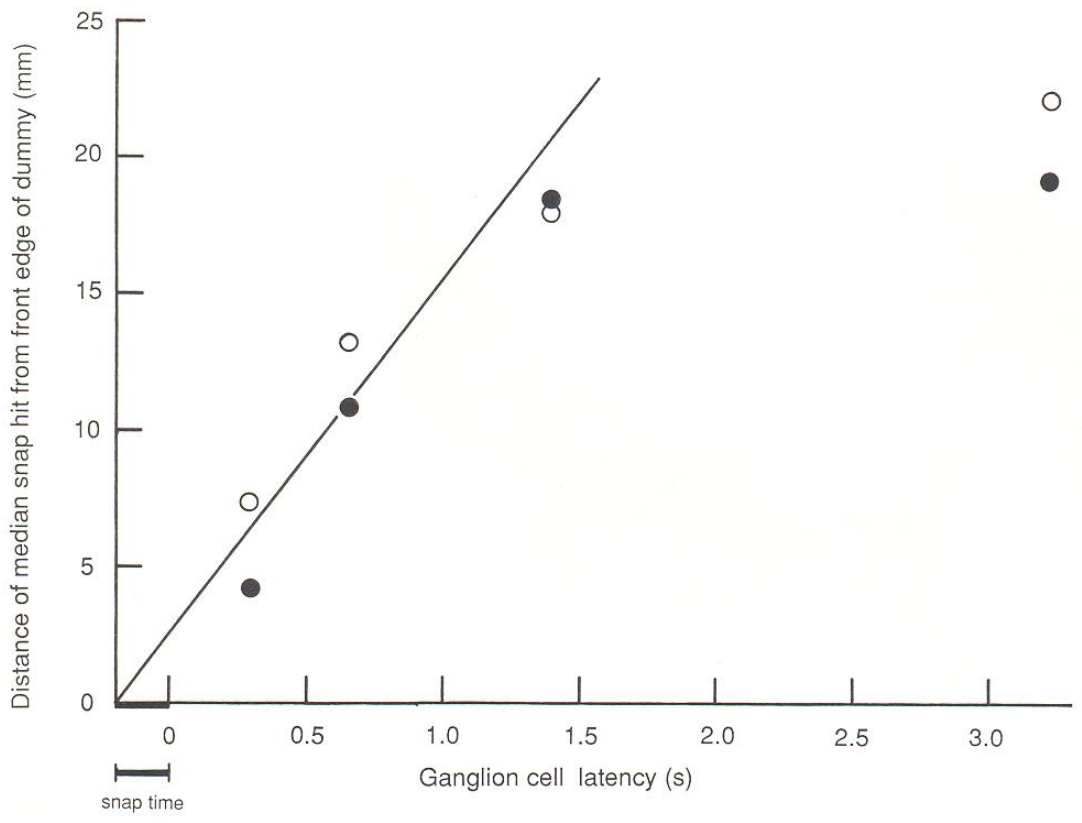

Fig. 8. Longitudinal distance of the median hit position from the front edge of the dummy $(\mathrm{mm})$ at the 4 intensities of the snapping experiments, plotted against median ganglion cell latencies to the equivalent retinal stimuli. Filled circles: data from Figs. 5 and 7. Open circles: hit position displacements calculated from all snaps, including snaps towards "disappearing" dummies. The straight line shows the prediction of the hypothesis that the displacements are solely due to the delay of the visual information reaching the brain. See text for details 
moving object not as it is at that moment, but as it was a moment ago. This problem is aggravated towards lower light intensities. Within a typical ganglion cell response latency at $0.02 \mathrm{Rh} * \mathrm{~s}^{-1}(2.9 \mathrm{~s})$ the worm-dummy would traverse twice its own length. Within the latency at the highest intensity in Fig. 6 (0.3 s) it would move only $20 \%$ of its length. Could this be the reason why snappings are displaced successively further to the rear as the light is dimmed?

We gave this idea the form of a simple hypothesis: The toad always aims at the front edge of the dummy as seen by its brain. The hit is displaced to the rear because of the visual delay (plus other minor delays), which means that the dummy is in a new position by the time the tongue hits the floor.

Under this hypothesis, the difference $\Delta \mathrm{x}$ between the $\mathrm{x}$-coordinate of the hit position and that of the dummy's front edge should grow in direct proportion to the delay, of which the ganglion cell latency L [s] forms the dominant part. We added a constant extra delay of $0.2 \mathrm{~s}$ for signal transmission from the retina to the brain, brain processing, and for the snap up to the moment when the tongue hits the floor. (This may be an underestimate, as the snap alone took $0.14 \mathrm{~s}$.) With dummy speed $13 \mathrm{~mm} / \mathrm{s}$, the predicted $\Delta \mathrm{x}[\mathrm{mm}]$ is

$\Delta \mathrm{x}=13 \cdot(\mathrm{L}+0.2)$

Figure 8 shows measured $\mathrm{x}$-deviations as functions of the latency of ganglion cell responses to the same stimulus intensities (filled circles, data from Figs. 5 and 7). The straight line plots Eq. (1). The data at the 3 higher intensities (i.e., for shorter ganglion cell latencies) fit the hypothesis well. The point for the lowest intensity, however, deviates strongly from the prediction. Although the largest increase in ganglion cell latency is found between the two lowest intensities, snap positions were not very different. This is not a methodological artifact caused by our decision to neglect snaps towards dummies that were disappearing from the window, because a parallel analysis that includes all snaps (open circles in Fig. 8) gives very much the same picture. At the lowest intensity, snaps are much less displaced than expected from ganglion cell latencies. It seems significative that this coincides with the sharp increase in snapping latencies (Fig. 4), showing that toads on average took time to contemplate ten passing dummies before snapping.

\section{Discussion}

\section{The absolute threshold}

The two most sensitive of the 25 ganglion cells studied responded to a large, long-duration stimulus isomerizing only one rhodopsin molecule per one hundred rods per second $\left(0.01 \mathrm{Rh} * \mathrm{~s}^{-1}\right.$, see Table 2$)$. This was also the absolute threshold for visually guided snapping at $15^{\circ} \mathrm{C}$ (Aho et al. 1988). Indeed, it is hard to imagine that effective prey-catching could occur under much lower illumination. The reason is this (assuming that toad species are similar with regard to the properties of their rhodopsins and rod physiology): toad rods produce spontaneous isomerization-like "events", which are randomly distributed in time and at $15{ }^{\circ} \mathrm{C}$ occur at an average rate of $0.016 \mathrm{~s}^{-1}$ per rod (data of Baylor et al. (1980) corrected for different numbers of rhodopsin molecules in rods of Bufo marinus and B. bufo). Every light signal that produces significantly lower isomerization rates must get swamped by this intrinsic rod noise (Copenhagen et al. 1987; Donner 1989b).

The absolute threshold intensity seems to be remarkably constant across different amphibian species. Experiments on the phototactic jumping of frogs (Rana temporaria and Rana pipiens) trying to escape from a dark bucket yielded a threshold of $0.009 \mathrm{Rh} * \mathrm{~s}^{-1}$ at $15-16{ }^{\circ} \mathrm{C}$ (Aho et al. 1987, 1993). Himstedt (1982) reports that the urodelan amphibian Salamandra salamandra snaps towards visual "prey" stimuli at an ambient light level of $10^{-6} \mathrm{~cd} / \mathrm{m}^{2}$, but not at $10^{-7} \mathrm{~cd} / \mathrm{m}^{2}$. The intensity of $525 \mathrm{~nm}$ light that produces $0.01 \mathrm{Rh} * \mathrm{~s}^{-1}$ in Bufo bufo rods corresponds to $1.4 \times 10^{-6} \mathrm{~cd} / \mathrm{m}^{2}$.

\section{The signal-to-noise ratio and latency of ganglion cell threshold responses}

The signal-to-noise ratio. Retinal ganglion cells can carry the visual information to the brain in two different ways: (1) the cells can maintain a continuous discharge of several spikes per second, which is modulated by light stimuli or (2) the cells can be silent in general and produce impulse discharges only in response to (statistically) significant illumination changes. In the former case (as in mammalians for example) the brain may reach conclusions about the occurrence of significant modulations of the light by summing minute changes in the discharges of many ganglion cells. In case (2) the individual ganglion cells decide what light modulations carry information that should be made available to the brain. Substantial evidence supports the view that most class 2 and 3 ganglion cells of the toad retina belong to the latter type (Copenhagen et al. 1987; Donner et al. 1990).

The notion of individual ganglion cells as decision makers telling the brain only about light changes that meet a certain criterion of statistical significance makes understandable how the behavioural threshold of the whole animal can be so close to that of sensitive single cells (cf. Aho et al. 1987, 1988, 1993; Donner 1989b). It also means that an analysis of the reliability, measured as a signal-to-noise ratio (SNR), of single-cell threshold responses is directly relevant for understanding behaviour.

Table 2 (rightmost column) gives the "input" SNR $\left(\mathrm{SNR}_{\mathrm{in}}\right)$ of threshold responses of the most sensitive ganglion cells, assuming that all variability stems from quantal fluctuations in the light and from spontaneous isomerization-like rod events occurring at a rate of 0.016 per rod per second (see above). The principles have been discussed and equations given elsewhere (Aho et al. 1987; Donner 1989b). Let it suffice here that: (1) The SNR (generally defined as signal mean divided by standard 
deviation) is a measure of reliability - the higher the $\mathrm{SNR}$, the less probable is it that the cell makes a "mistake" (responds though there is no significant light modulation or fails to report a significant modulation); (2) $\mathrm{SNR}_{\text {in }}$ (as in Table 2) gives an upper bound for the actual $\mathrm{SNR}$ of the cell's physiological response $\left(\mathrm{SNR}_{\text {out }}<\mathrm{SNR}_{\text {in }}\right)$. However, the "best" toad and frog ganglion cells have been found to get close to this maximum reliability (Copenhagen et al. 1987; Aho et al. 1987; Donner 1989b).

Summation time and $S N R$. The average $\mathrm{SNR}_{\text {in }}$ for threshold responses in Table 2 is 2.7. If $\mathrm{SNR}_{\text {out }}$ is not much lower, this means that the probability of a false response within any randomly selected 1.65 -s period (the mean summation time) is lower than 0.004 - "false alarm" would be given less than once per $7 \mathrm{~min}$. Thus, the threshold response of a sensitive toad ganglion cell can provide fairly reliable information that something occurred a few seconds ago in a region subtending roughly $5^{\circ}$ of visual angle. If, however, the summation times of the cells in Table 2 were shortened by $50 \%$ (to $0.83 \mathrm{~s}$ on average) with unchanged threshold intensities, the mean $\mathrm{SNR}_{\text {in }}$ at threshold would drop to $2.7 / \sqrt{2}=1.9$ (Donner et al. 1990). This means that the rate of false responses would rise to an unacceptable level of more than one per $30 \mathrm{~s}$. Clearly, reliable signalling at light intensities close to the snapping threshold is not compatible with significantly shorter summation times than those observed.

It may be asked whether effective temporal summation here can be longer than $1.5 \mathrm{~s}$, the time in which the $20 \mathrm{~mm}$ dummy moving at $13 \mathrm{~mm} / \mathrm{s}$ passes any point in the visual field. We have no certain answer. In some cases, toads were observed to maintain fixation by following the dummy with their gaze even at the lowest intensity. Yet, on average it is likely that the speed of the dummy will limit temporal summation. This could be one reason for the slightly lower absolute sensitivity here compared with our earlier study (Aho et al. 1988) where the dummy moved at only $8.3 \mathrm{~mm} / \mathrm{s}$ (and thus was present for $2.4 \mathrm{~s}$ at any one point).

Latency and summation time. It is self-evident that the latency of the response to a threshold step of light must be at least as long as the summation time. In reality, it will be significantly longer because of the slowness of dark-adapted rod responses to dim light (see e.g. Baylor et al. 1979, 1980). This slowness, in turn, is an inevitable consequence of the need to amplify single photon signals through cascades of enzymatic reactions (see e.g. Lamb and Pugh 1992). Thus, responses to low-intensity ONsteps rise slowly (in principle asymptotically) towards a final amplitude. Assuming that the ganglion cell response starts when the underlying rod response has risen to $95 \%$ of its plateau amplitude, a summation time of $1.65 \mathrm{~s}$ would mean that the latency of a near-threshold ON-step response is longer than $3 \mathrm{~s}$ (assuming 4 steps in the cascade, see Donner (1989a)). To this would be added a more or less constant neural transmission delay.

Note that the common dependence of summation time and latency on rod response kinetics also means that both will be extended like the rod response when temperature is lowered (Aho et al. 1993; $\mathrm{Q}_{10}=2.2$ for toad rods: Lamb 1984). The coolness of night brings a longer summation time (and lower retinal noise, both favouring visual sensitivity) but also longer visual latencies. Luckily, woodlice and worms slow down, too.

Latency and SNR. To summarize, ganglion cells serving prey-catching at very low intensities are subject to the following constraints: (1) to reach sufficient spatial resolution, they must have receptive fields of restricted size; (2) to collect a significant number of photon signals from such a limited rod population (to ensure that responses are reliable) they must have summation times close to $2 \mathrm{~s}$; (3) a long summation time is inevitably associated with an even longer response latency. Thus the threshold responses of ganglion cells that are useful for localizing prey at $0.01-0.02 \mathrm{Rh} * \mathrm{~s}^{-1}$ must have latencies of $3 \mathrm{~s}$ or more.

\section{Precision and accuracy of snapping}

Precision. Decreasing the illumination was associated with a successively larger backward displacement of median snap position (lower accuracy), but the swarms of snaps remained quite well collected (little change in precision). The latter observation seems to imply that the random dispersion is largely associated with the act of snapping rather than "blurred" visual information. The eagerness to snap that was evident in many toads at the highest intensities may not be conducive to precision. And on the other hand, the fairly high SNR of ganglion cell responses at the absolute threshold (Table 2) would seem to imply that once the dummy is detected at the retinal level, its position is quite well-defined. The difficulties are due to the movement, which makes the position information obsolete before it becomes available to the brain.

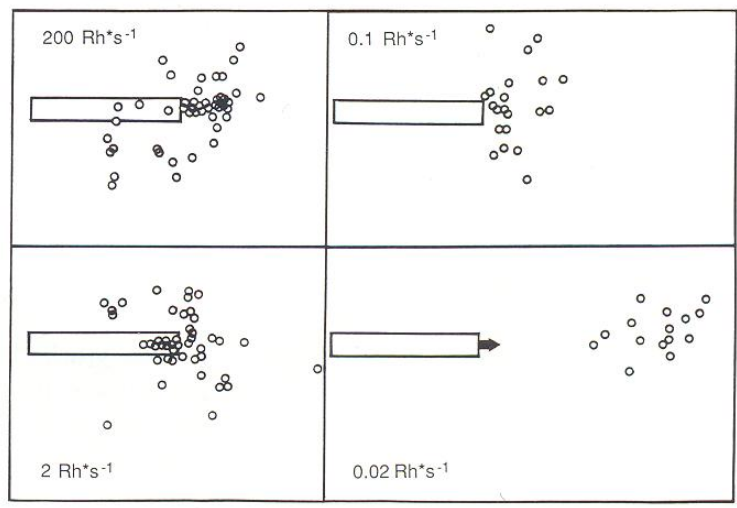

Fig. 9. Visualization of snap hit positions relative to the dummy as shown by the visual information reaching the brain from the retina at the moment the snap was initiated. (At the lowest intensity, one hit fell outside the picture) 
Accuracy. The "visual delay" hypothesis quite succesfully accounts for tongue hit positions at higher intensities (Fig. 8). Most intriguing, however, is the deviation from this hypothesis just at threshold, revealing a mechanism for correcting snapping direction that vastly improves the chance of hitting the prey. Figure 9 is an attempt to visualize the situation in terms of the information that reaches the brain through the optic nerve fibers at the moment the snap is initiated. It is a replot of Fig. 5 where the rectangle in each panel has been displaced "backwards" by the distance the dummy would traverse in a time equal to the ganglion cell latency plus $0.2 \mathrm{~s}$. It shows how, at the 3 higher intensities, the snaps are aimed at the front edge of the dummy image, but at the lowest intensity at a point some $2 \mathrm{~cm}$ in front of it.

Thus, close to their absolute threshold, toads have a correcting mechanism that offsets the retinal delay. It is noteworthy that the toads at the lowest intensities usually watched the passage of many dummies before snapping (Fig. 4), and hence in principle had the opportunity to form an inner model of the regularly moving prey dummies to guide the correction.

\section{Conclusion}

The high visual sensitivity of toads hunting on a cool night depends on several structural and functional characteristics: large pupil, fairly long rod outer segments, long rod summation times and low retinal noise. The price for collecting photons over long times is that vision becomes slow. Since Bufo bufo snaps nearly exclusively at moving objects, it is conceivable that it has developed strategies for hitting the prey in spite of this slowness. In the present experiments, the hits at moderately low light intensities were regularly displaced along the dummy in a way indicating that snaps were directed towards the front edge of the moving target as defined by the visual information reaching the brain from the retina in the snap-initiating moment. At nearthreshold intensities, however, the toads snapped in front of the position predicted by this hypothesis. Clearly, such a strategy can be successful only with predictably moving prey. Thus, while there are fundamental physical and anatomical constraints to the photosensitivity of a toad, more complex considerations determine the lowest light level where visually guided snapping is still effective in prey-catching.

Acknowledgements. We thank Ms. Nanna Fyhrquist for technical assistance and Mr. Ake Vuorisalo for making the photographs from which pupil sizes were measured. This work was supported by the Academy of Finland (grant 01/1011872) and the Oskar Öflund Foundation.

\section{References}

Aho A-C, Donner K, Hydén C, Reuter T, Orlov OY (1987) Retinal noise, the performance of retinal ganglion cells, and visual sensitivity in the dark-adapted frog. J Opt Soc Am A 4:2321-2329

Aho A-C, Donner K, Hydén C, Larsen LO, Reuter T (1988) Low retinal noise in animals with low body temperature allows high visual sensitivity. Nature (Lond) 334:348-350

Aho A-C, Donner K, Reuter T (1993) Retinal origins of the temperature effect on absolute visual sensitivity in frogs. J Physiol (Lond) 463:501-521

Bäckström A-C, Hemilä S, Reuter T (1978) Directional selectivity and colour coding in the frog retina. Med Biol 56:76-83

Baylor DA, Hodgkin AL, Lamb TD (1974) The electrical response of turtle cones to flashes and steps of light. J Physiol (Lond) 242:685-727

Baylor DA, Lamb TD, Yau K-W (1979) Rod responses to single photons. J Physiol (Lond) 288:613-634

Baylor DA, Matthews G, Yau K-W (1980) Two components of electrical dark noise in toad retinal rod outer segments. J Physiol (Lond) 309:591-621

Copenhagen DR, Donner K, Reuter T (1987) Ganglion cell performance at absolute threshold in toad retina: effects of dark events in rods. J Physiol (Lond) 393:667-680

Donner K (1981) Receptive fields of frog retinal ganglion cells response formation and light-dark-adaptation. J Physiol (Lond) 319: $131-142$

Donner K (1987) Adaptation-related changes in the spatial and temporal summation of frog retinal ganglion cells. Acta Physiol Scand 131:479-487

Donner K (1989a) Visual latency and brightness: an interpretation based on the responses of rods and ganglion cells in the frog retina. Visual Neurosci $3: 39-51$

Donner K (1989b) The absolute sensitivity of vision: can a frog become a perfect detector of light-induced and dark rod events? Physica Scripta 39: 133-140

Donner KO, Reuter T (1962) The spectral sensitivity and photopigment of the green rods in the frog's retina. Vision Res $2: 357-372$

Donner K, Copenhagen DR, Reuter T (1990) Weber and noise adaptation in the retina of the toad Bufo marinus. J Gen Physiol 95: 733-753

du Pont JS, de Groot PJ (1974) A schematic dioptric apparatus for the frog's eye (Rana esculenta). Vision Res 16:803-810

Eikmanns K-H von (1955) Verhaltensphysiologische Untersuchungen über den Beutefang und das Bewegungssehen der Erdkröte (Bufo bufo L.). Z Tierpsychol 12:229-253

Ewert J-P (1967) Untersuchungen über die Anteile zentralnervöser Aktionen an der taxisspezifischen Ermüdung beim Beutefang der Erdkröte (Bufo bufo L.). Z Vergl Physiol 57:263-298

Ewert J-P, Hock F (1972) Movement-sensitive neurones in the toad's retina. Exp Brain Res 16:41-59

Ewert J-P, Borchers H-W, Wietersheim A v (1978) Question of prey capture detectors in the toad's Bufo bufo (L.) visual system: A correlation analysis. J Comp Physiol 126:43-47

Govardovskii VI, Zueva LV (1974) Spectral sensitivity of the frog eye in the ultraviolet and visible region. Vision Res 14:1317-1321

Grüsser O-J, Grüsser-Cornehls U (1968) Neurophysiologische Grundlagen visueller angeborener Auslösemechanismen beim Frosch. Z Vergl Physiol 59: 1-24

Hemilä S, Reuter T (1981) Longitudinal spread of adaptation in the rods of the frog's retina. J Physiol (Lond) 310:501-528

Himstedt W (1982) Prey selection in salamanders. In: Ingle DJ, Goodale MA, Mansfield RJW (eds) The analysis of visual behaviour. The MIT Press, Cambridge, Mass, pp 47-66

Jagger WS (1988) Optical quality of the eye of the cane toad Bufo marinus. Vision Res 28:105-114

Lamb TD (1984) Effects of temperature changes on toad rod photocurrents. J Physiol (Lond) 346:557-578

Lamb TD, Pugh EN Jr (1992) G-protein cascades: gain and kinetics. Trends Neurosci 15:291-298

Larsen LO (1984) Feeding in adult toads: physiology, behaviour, ecology. Vidensk Meddr Dansk Naturh Foren 147:97-116

Larsen LO (1992) Feeding and digestion. In: Feder ME, Burggren 
WW (eds) Environmental physiology of the amphibians. The University of Chicago Press, Chicago, pp 378-394

Larsen LO, Pedersen JN (1982) The snapping response of the toad, Bufo bufo, towards prey dummies at very low light intensities. Amphibia-Reptilia 2:321-327

Lescure J (1965) L'alimentation et le comportement de prédation chez Bufo bufo (Linnaeus, 1758). Thès Fac Sci Univ Paris, Série 4:4657

Lescure J (1982) Le comportement alimentaire. In: Grassé PP (ed) Traité de Zoologie, Amphibiens 2:215-222

Lock A, Collett T (1979) A toad's devious approach to its prey: a study of some complex uses of depth vision. J Comp Physiol 131: 179-189
Mansfield RJW, Daugman JG (1978) Retinal mechanisms of visual latency. Vision Res 18: 1247-1260

Maturana HR, Lettvin JY, McCulloch WS, Pitts WH (1960) Anatomy and physiology of vision in the frog (Rana pipiens). J Gen Physiol 43:129-175

Putnam RW, Bennett AF (1981) Thermal dependence of behavioural performance of anuran amphibians. Anim Behav 29:502-509 Reuter T, Virtanen K (1976) Color discrimination mechanisms in the retina of the toad (Bufo bufo). J Comp Physiol 109:337-343 Schneider D (1954) Beitrag zu einer Analyse des Beute- und Fluchtverhaltens einheimischer Anuren. Biol Zbl 73:225-282 